\title{
Physical Properties and Photoreactivity of Cycloaliphatic Epoxy Resins Cured by UV-Induced Cationic Polymerization
}

\author{
Atsushi Udagawa, Yasuhiko Yamamoto, Yoshio Inoue, \\ and Riichirô CHÛJô \\ Department of Biomolecular Engineering, Tokyo Institute of Technology, \\ O-okayama 2-chome, Meguro-ku, Tokyo 152, Japan
}

(Received October 13, 1990)

\begin{abstract}
In the UV cured cycloaliphatic epoxy resins consisting of 3,4-epoxycyclohexylmethyl-3',4'-epoxycyclohexane carboxylate and triphenylsulfonium hexafluoroantimonate (TPSHA), which is a photoinitiator for cationic polymerization, the TPSHA residue was found to act as plasticizer above the initiator concentration of approximately $2 \mathrm{wt} \%$, while act as antiplasticizer below this concentration. The photoreactivity of the uncured samples was investigated by using differential scanning calorimetry and tack free time measurements, and the physical properties of the UV cured samples were investigated by using dynamic mechanical measurements, thermal gravimetry, and high-resolution solid-state ${ }^{13} \mathrm{C}$ NMR spectroscopy. Although no significant difference in the chemical structure was detected for the cured samples containing various concentrations of the photoinitiator, ranging 0.5 to $9 \mathrm{wt} \%$, the TPSHA concentration had a strong influence on the thermal stability and the glass-transition temperature of the samples. The ${ }^{13} \mathrm{C}$ NMR spin-lattice relaxation time and spin-lattice relaxation time in the rotating frame provided information on the molecular motions of the epoxy polymers, which indicates the plasticization and antiplasticization effects of the TPSHA residue.

KEY WORDS Epoxy Resin / UV Cure / Solid-State ${ }^{13} \mathrm{C}$ NMR / Dynamic Mechanical Properties / Photoreactivity /
\end{abstract}

Onium salts possessing a non-nucleophilic anion, such as $\mathrm{PF}_{6}{ }^{-}, \mathrm{SbF}_{6}{ }^{-}, \mathrm{AsF}_{6}{ }^{-}$, or $\mathrm{BF}_{4}{ }^{-}$, have been used as initiators for photo-induced cationic polymerization of ultraviolet (UV) curable epoxy resins. ${ }^{1,2}$ The photolysis of the onium salts leads the production of the acid $\mathrm{H}^{+} \mathrm{X}^{-}$, where $\mathrm{X}^{-}$is the counter-anion, which becomes the polymerization initiator. The onium salts are classified into three categories $^{1,2}$ : diazonium, diaryliodonium, and triarylsulfonium salts. For general use, the triarylsulfonium salts are considered as one of the best photoinitiators ${ }^{3-7}$ because of their wide range of UV absorption, good heat stability, and long pot life.

The cure rate of the UV curable epoxy resins is affected by the factors such as the chemical structures of reactant epoxides and photo- initiators, initiator concentration, curing temperature, and the nature of the UV light used. ${ }^{1,2}$ Crivello et al..$^{3,8}$ reported that maximum cure rate of a cycloaliphatic epoxy resin, 3,4-epoxycyclohexylmethyl-3', 4'-epoxycyclohexane carboxylate (ECC), was obtained with $2-3 \%$ by weight $(\mathrm{wt} \%)$ of triphenylsulfonium hexafluoroarsenate or with $3 \mathrm{wt} \%$ diphenyliodonium hexafluoroarsenate. At the concentrations below $1 \mathrm{wt} \%$, photopolymerization is relatively slow. Increasing the concentration above $3 \mathrm{wt} \%$ produces no further increase in the rate. ${ }^{8}$ Watt $^{2}$ obtained similar results using ECC containing p-methoxybenzene diazonium hexafluorophosphate. Therefore, epoxides containing $2-3 \mathrm{wt} \%$ onium salt photoinitiator have been believed to be practical for UV curable epoxy resin systems 
from the consideration of both the rate of cure and the costs of the expensive initiator. However the effect of the initiator concentration on the physical properties of the UV curable epoxy resins has not yet been fully explored, because the previous works mentioned the above were concentrated on the cure rate. After the UV curable system was irradiated by UV light, the initiator residue (fragments and unreacted initiator) remains inside of the cured resin. Our studies have been, therefore, aimed at revealing the effect of the photoinitiator residue on the physical properties of the UV cured epoxy resin.

In this paper, the photoreactivity of the UV curable cycloaliphatic epoxy resin system consisting of ECC and triphenylsulfonium hexafluoroantimonate (TPSHA) was investigated using differential scanning calorimetry (DSC) and tack free time measurements, and the physical properties of the UV cured resins were investigated using dynamic mechanical measurements, thermal gravimetry (TG), and high-resolution solid-state ${ }^{13} \mathrm{C}$ NMR spectroscopy.

The modified DSC, referred to as photoDSC, has been used to monitor the reaction of photopolymerization. ${ }^{9-14} \mathrm{UV}$ light is introduced to the sample and reference cells of a differential scanning calorimeter, hence the enthalpy of photopolymerization of UV-irradiated samples in situ. It is possible to calculate the rate and conversion of the reaction from the enthalpy date obtained by the photo-DSC analysis. The tack free time measurement is easy and covenient procedure for evaluating the photoreactivity of UV curable systems. ${ }^{15}$ The photoreactivity of the UV curable samples are discussed from the the results obtained by the photo-DSC and the tack free time measurement.

The cross-polarization ${ }^{16,17} /$ magic-angle- $^{2}$ spinning ${ }^{18,19}$ (CP/MAS) ${ }^{13} \mathrm{C}$ NMR technique provided information on the chemical structure of the cured samples, while the TG analysis revealed their thermal stability. The effects of the initiator concentration on the glass transition temperature, $T_{\mathrm{g}}$, and the crosslinking density, $\rho$, of the UV cured epoxy resins are discussed in terms of the temperature dependence of the complex Young's modulus, $E^{*}\left(=E^{\prime}+i E^{\prime \prime}\right.$, where $E^{\prime}$ is storage modulus and $E^{\prime \prime}$ is loss moculus), obtained from the dynamic mechanical measurements at $1 \mathrm{~Hz}$.

Finally, molecular dynamics of the UV cured epoxy resins were investigated using two high-resolution solid-state ${ }^{13} \mathrm{C}$ NMR relaxation times; spin-lattice relaxation time, $T_{1}^{\mathrm{C}}$, and spin-lattice relaxation time in the rotating frame, $T_{1 \rho}^{\mathrm{C}}$. These relaxation times have been used previously to characterize the molecular motions of polymers in solids, ${ }^{20-41}$ including cured epoxy resins ${ }^{20-24}$ and polymer-plasticizer systems. ${ }^{25-29}$. At room temperatures, Garroway et $a .^{20,21}$ have found that the $T_{1 \rho}^{\mathrm{C}}$ of a cured epoxy resin is dominated by spin-lattice relaxation process rather than spin-spin relaxation process, thus reflects the molecular motions in the mid-kilohertz regime. In the megahertz regime, it is accepted unobscurely that the $T_{1}^{\mathrm{C}}$ is completely spinlattice or motional in origin. The $T_{1}^{\mathrm{C}}$ and $T_{1 \rho}^{\mathrm{C}}$ are measured for the UV cured samples in order to study the dependence of the concentration of the photoinitiator added.

\section{EXPERIMENTAL}

\section{Materials}

A cycloaliphatic epoxide, 3,4-epoxycyclohexylmethyl-3', $4^{\prime}$-epoxycyclohexane carboxylate (ECC), and a photoinitiator, triphenylsulfonium hexafluoroantimonate (TPSHA), were supplied from Union Carbide and $3 \mathrm{M}$, respectively, and were used without further purification. The structural formula of ECC is given in Figure 1. The initiator concentrations of UV curable samples investigated are listed in Table I.

\section{UV Curing Procedures}

The samples were poured into a UV- 
Table I. Photoreactivity and dynamic mechanical properties of UV curable epoxy resins consisting of ECC and TPSHA as a function of the photoinitiator concentration

\begin{tabular}{|c|c|c|c|c|c|c|}
\hline \multirow{2}{*}{ Sample } & $\begin{array}{l}\text { Photoinitiator } \\
\text { concentrtration }\end{array}$ & \multirow{2}{*}{$\begin{array}{l}\text { Tack free } \\
\text { time }^{a}\end{array}$} & \multirow{2}{*}{$\frac{r^{\mathrm{b}}}{\%}$} & \multirow{2}{*}{$\frac{T_{\mathrm{g}}^{\mathrm{c}}}{{ }^{\circ} \mathrm{C}}$} & \multirow{2}{*}{$\begin{array}{l}\log \left(E^{\prime} / P_{\mathrm{a}}\right) \\
\text { at } T_{\mathrm{g}}+40^{\circ} \mathrm{C}\end{array}$} & \multirow{2}{*}{$\frac{\rho^{\mathrm{d}} / 10^{4}}{\mathrm{molm}^{-3}}$} \\
\hline & $w t \%$ & & & & & \\
\hline A & 0.50 & 6 & 2.6 & 193 & 8.19 & 1.24 \\
\hline B & 0.74 & 4 & 2.3 & 183 & 8.24 & 1.51 \\
\hline $\mathrm{C}$ & 0.99 & 4 & $\sim 0$ & 164 & 8.23 & 1.43 \\
\hline D & 1.96 & 3 & $\sim 0$ & 161 & 8.21 & 1.51 \\
\hline $\mathrm{E}$ & 2.91 & 3 & $\sim 0$ & 150 & 8.18 & 1.32 \\
\hline $\mathrm{F}$ & 4.76 & 3 & $\sim 0$ & 145 & 8.21 & 1.41 \\
\hline $\mathrm{G}$ & 9.09 & 3 & 1.9 & 127 & 8.28 & 1.69 \\
\hline $\begin{array}{ll}\text { a } & \text { The } \\
\text { b See e } \\
\text { c The } \\
\text { d See } \mathrm{e}\end{array}$ & $\begin{array}{l}\text { of passes throug } \\
\text { rature of } \tan \delta \text { max }\end{array}$ & $\begin{array}{l}\text { UV irradi } \\
\text { at } 1 \mathrm{~Hz} \text {. }\end{array}$ & system & ${ }^{2}$ per & the waveleng & of $350 \mathrm{~nm}$ ). \\
\hline
\end{tabular}<smiles>CC(C)(C)C1CCCCC1COC(=O)C1CCC2CCC1O2</smiles><smiles>COC1CC(COC(=O)C2CCC(OC)[C@@H](OC)C2)CC[C@@H]1OC</smiles>

Figure 1. Structural formula of 3,4-epoxycyclohexylmethyl-3', $4^{\prime}$-epoxycyclohexane carboxylate (ECC) and the reaction occurring in the cationic polymerization of ECC.

transparent mold consisting of a pair of quartz glass plates, $5 \mathrm{~mm}$ thick, and a silicone rubber spacer, $1 \mathrm{~mm}$ thick, and were irradiated with a 300 W high-pressure $\mathrm{Hg}$ lamp for $1 \mathrm{~h}$. The distance was $15 \mathrm{~cm}$ between the lamp and the sample. The UV-irradiated samples were post-cured in an oven an $120^{\circ} \mathrm{C}$ for $1 \mathrm{~h}$ and then at $150^{\circ} \mathrm{C}$ for $1 \mathrm{~h}$.

\section{DSC Measurements}

A photo-DSC system consisting of a Perkin Elmer DSC-4 differential scanning calorimeter and a Macam Photometrics Flexicure model
UVLS102 UV light source (Philips HPA400 Hg lamp) was used for measurements. UV light was guided through two light pipes leading to the sample and reference cells, which were kept at $40^{\circ} \mathrm{C}$, of the calorimeter. The light intensity at the cells was approximately $1 \mathrm{~mW} \cdot \mathrm{cm}^{-2}$ at the wavelength of $350 \mathrm{~nm}$. Approximately $3 \mathrm{mg}$ of an uncured sample was weighed in an aluminum pan, and was set at the sample cell without an aluminum cover. An empty pan without a cover was used as reference. The photo-DSC data were acquired for $25 \mathrm{~min}$ at $40^{\circ} \mathrm{C}$ under continuous UV-irradiated conditions. After the photo-DSC measurement, a conventional thermal scan was carried out successively, using the irradiated sample in the pan at the heating rate of $20^{\circ} \mathrm{C} \mathrm{min}-1$ in the temperature range of $40-250^{\circ} \mathrm{C}$.

The integrated peak intensities of the photo-DSC and the following DSC thermograms were calculated with the DSC-4 data processor, and were represented as the heat of the photoreaction, $\Delta H_{\mathrm{P}}$, and the heat of the post-curing reaction, $\Delta H_{\mathrm{PC}}$, respectively. The total heat of reaction, $\Delta H_{\mathrm{T}}$, was calculated as the sum of the two terms; $\Delta H_{\mathrm{T}}=\Delta H_{\mathrm{P}}+\Delta H_{\mathrm{PC}}$. 


\section{A. Udagawa et al.}

Tack Free Time Measurements

The uncured sample was coated on a mild steel plate with a $50 \mu \mathrm{m}$ applicator, and was UV-irradiated with an Ushio Electronics UVC-183 instrument $\left(80 \mathrm{~W} \mathrm{~cm}^{-1}\right.$ high-pressure $\mathrm{Hg}$ lamp) equipped with a conveyor system adjusted to $0.1 \mathrm{~J} \mathrm{~cm}^{-2}$ per pass at the wavelength of $350 \mathrm{~nm}$; the sample was placed $15 \mathrm{~cm}$ away from the lamp and the irradiation time was $3.7 \mathrm{~s}$ per pass. The tack free time was defined as the number of passes through the instrument required for the coating surface to become sufficiently non-tacky that it will not pull cotton linters from a ball of absorbent cotton pressed firmly against it. ${ }^{2}$

\section{Solid-State NMR Measurements}

The ${ }^{13} \mathrm{C}$ CP/MAS, dipolar decoupling (DD)/MAS, ${ }^{42}$ and pulse saturation transfer (PST)/MAS ${ }^{43}$ experiments were carried out at the ${ }^{13} \mathrm{C}$ resonance frequency of $67.9 \mathrm{MHz}$ on a JEOL GSX-270 spectrometer with a $\mathrm{CP} / \mathrm{MAS}$ accessory. Typical spectra were recorded using $27 \mathrm{kHz}$ spectral width, $8 \mathrm{k}$ data points, $2000-4000$ accumulations at room temperatures. The cured sample was packed in a cylindrical ceramic rotor. The spinning rate of about $5.2 \mathrm{kHz}$ was used for MAS. The CP/MAS spectra were obtained with $1 \mathrm{~ms}$ contact time and $5 \mathrm{~s}$ pulse duration. The typical $90^{\circ}$ pulse width and spin-lock field were $4.5 \mu \mathrm{s}$ and $60 \mathrm{kHz}$, respectively, for both ${ }^{1} \mathrm{H}$ and ${ }^{13} \mathrm{C}$ on the Hartmann-Hahn condition. ${ }^{16}$ The DD/MAS spectra were observed using a $45^{\circ}$ $\left({ }^{13} \mathrm{C}\right)$ pulse under high-power ${ }^{1} \mathrm{H}$ decoupling $(60 \mathrm{kHz})$. The pulse duration time was set to at least three times of the longest $T_{1}^{\mathrm{C}}$ of the sample, and was typically $70 \mathrm{~s}$. The PST/MAS spectra were measured on the same conditions as in the CP/MAS experiments. ${ }^{13} \mathrm{C}$ Chemical shifts were calibrated through the methylene ${ }^{13} \mathrm{C}$ signal of adamantane $(29.5 \mathrm{ppm})$ relative to tetramethylsilane.

The ${ }^{13} \mathrm{C} \mathrm{CP}$ spin-lattice relaxation experiments were performed by using the Torchia's method. ${ }^{44}$ Delay times between ${ }^{13} \mathrm{C} 90^{\circ}$ pulses ranged from 0.5 to $15 \mathrm{~s}$. The ${ }^{13} \mathrm{C}$ spin-lattice relaxation times, $T_{1}^{\mathrm{C}}$, were calculated using the standard procedures. ${ }^{44}$

The ${ }^{13} \mathrm{C}$ spin-lattice relaxation times in the rotating frame, $T_{1 \rho}^{\mathrm{C}}$, were obtained using the standard procedures. ${ }^{30}$ Delay times after the ${ }^{1} \mathrm{H}$ radio-frequency field was removed ranged from 1 to $10 \mathrm{~ms}$.

\section{TG Measurements}

The TG analysis of the cured samples was carried out by using a DuPont 951 thermal gravimetric analyzer and a DuPont 9900 data processor with the heating rate of $20^{\circ} \mathrm{C} \cdot \mathrm{min}^{-1}$ in the temperature range from room temperature to $500^{\circ} \mathrm{C}$ under the air-flow conditions. The decomposition temperatures, $T_{98 \%}, T_{95 \%}$, and $T_{90 \%}$, were defined as the temperatures at which the weight loss amounts to 2, 5, and $10 \%$, respectively, by thermal decomposition, and were calculated by the data processor.

\section{Dynamic Mechanical Measurements}

The complex Young's moduli, $E^{*}$, of the cured samples were obtained with a Rheometrics RSA-2 solid analyzer at $1 \mathrm{~Hz}$ at $2^{\circ} \mathrm{C}$ intervals in the temperature range from 50 to $250^{\circ} \mathrm{C}$. Temperature was raised by step, set to $5^{\circ} \mathrm{C}$ for every $30 \mathrm{~s}$. The bending test was carried out using the bar shaped sample, $50 \mathrm{~mm}$ length, $6 \mathrm{~mm}$ width, and $1 \mathrm{~mm}$ thick, set on the dual cantilever bending fixture with $0.1 \%$ strain. The glass-transition temperature, $T_{\mathrm{g}}$, was defined as the temperature of maximum $\tan \delta\left(=E^{\prime \prime} / E^{\prime}\right)$. The rubber-modulus was defined as the storage modulus at the temperature of $T_{\mathrm{g}}+40^{\circ} \mathrm{C}$.

\section{RESULTS AND DISCUSSION}

\section{Photoreactivity}

The effect of the TPSHA concentration on the cure rate of ECC was evaluated by the tack free times listed in Table I. At the concentrations below $1 \mathrm{wt} \%$, the photopolymerization is relatively slow. When the concentration of 
TPSHA is reduced to $0.1 \mathrm{wt} \%$, the sample remains fluid and tacky. Increasing the concentration above $2 \mathrm{wt} \%$ leads no significant change in the rate. These results are in good agreement with previous works. ${ }^{2,3,8}$

The values of $\Delta H_{\mathrm{P}}$ and $\Delta H_{\mathrm{T}}$ obtained from the photo-DSC analyses of the samples are plotted against the photoinitiator concentration in Figure 2. The $\Delta H_{\mathrm{T}}$ curve exhibits similar behavior to the $\Delta H_{\mathrm{P}}$ curve; there is a marked TPSHA concentration dependence on both $\Delta H_{\mathrm{P}}$ and $\Delta H_{\mathrm{T}}$ at the concentration below $1 \mathrm{wt} \%$, while raising the concentration above $1 \mathrm{wt} \%$ produces no further increase. The values of $\Delta H_{\mathrm{P}} / \Delta H_{\mathrm{T}}$ are almost constant in the TPSHA concentration range of $1-9 \mathrm{wt} \%$. The mean value of $\Delta H_{\mathrm{P}} / \Delta H_{T}$ is 0.47 at $1-9 \mathrm{wt} \%$, thus the conversion of the photoreaction alone is less than $50 \%$, indicating the important role of the post-curing for the completion of the curing process. The results of both the tack free time measurement and the photo-DSC analysis indicate that there is no significant effect of the initiator concentration on the photoreactivity of the UV curable samples in the concentration range of $1-9 \mathrm{wt} \%$.

\section{High-Resolution Solid-State ${ }^{13}$ C NMR Spectra}

The CP/MAS spectra of Samples A, C, E, and $G$ are shown in the traces $a, b, c$, and $d$, respectively, in Figure 3. The broad resonances of the spectra are attributed to the heterogeneous chemical environment due to the crosslinked network structure of the cured epoxy polymers. ${ }^{21}$ The signal assignments were done on the basis of the solution ${ }^{13} \mathrm{C}$ NMR assignments of $\mathrm{ECC}^{45}$. The resonances at $10-50 \mathrm{ppm}$ were assigned to $\mathrm{C}_{\mathrm{A}}$ carbons and those at $60-90 \mathrm{ppm}$ were assigned to $C_{B}$ and $\mathrm{C}_{\mathrm{B}^{\prime}}$ carbons. The broad resonance at 110 $150 \mathrm{ppm}$, which is absent in the the solution spectrum of $\mathrm{ECC}^{45}$ and whose intensity becomes stronger as the initiator concentration increases, would arise from the TPSHA residue. The resonance at $175 \mathrm{ppm}$ was assigned to $\mathrm{C}_{\mathrm{C}}$. The resonance at $55 \mathrm{ppm}$, which clear-

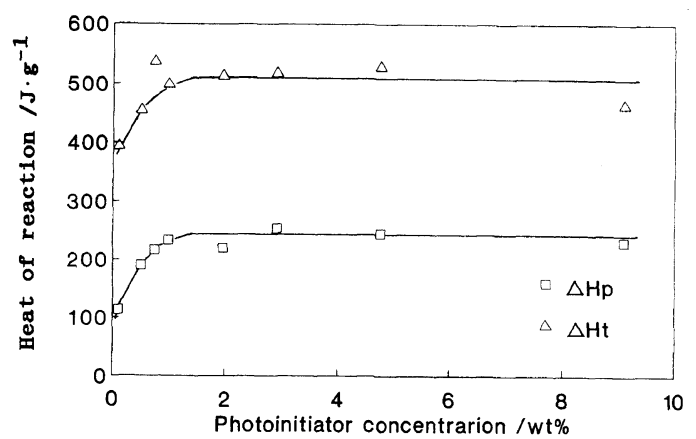

Figure 2. TPSHA concentration dependence of the heat of the photoreaction, $\Delta H_{p}$, and the total heat of the photoreaction and following thermal reaction, $\Delta H_{\mathrm{T}}$, of the samples.

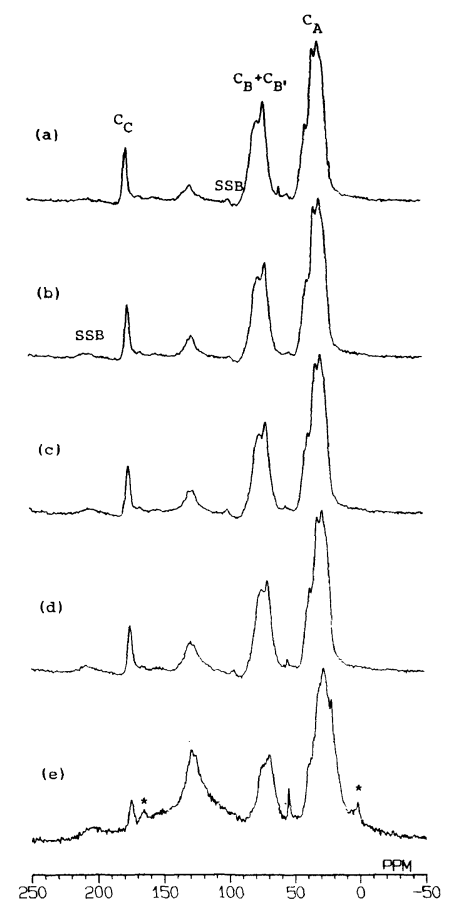

Figure 3. ${ }^{13} \mathrm{C} \mathrm{CP} / \mathrm{MAS}$ spectra of cured Sample A (a), Sample C (b), Sample E (c), and Sample G (d), and PST/MAS spectrum of cured Sample G (e). The peaks indicated by $*$ in trace e arised from the spinning-rotor.

ly appears as a sharp signal in the traces a and $d$, was assigned to the unreacted epoxy carbons. This resonance completely disappears in the trace $b$, thus the Sample $C$ should be completely cured. The chemical shifts and the peak shapes of all resonances, except arising 
from the TPSHA residue and the unreacted epoxy group, are the same in the $\mathrm{CP} / \mathrm{MAS}$ spectra of all samples, indicating the identical chemical structure of the cured epoxy polymer in the samples. Hence, the chemical structure is independent of the initiator concentration in the range of $0.5-9 \mathrm{wt} \%$.

The PST/MAS spectrum of Sample $G$ is shown in the trace e in Figure 3. It is noted that the PST/MAS technique, in contrast with the CP/MAS technique, enhances the peak intensity of the resonances arising from the molecules with relatively rapid motions in the solid sample. ${ }^{43}$ The increase in the signal intensity of the resonances arising from the TPSHA residue and the unreacted epoxy group relative to those from the epoxy polymer in trace e clearly indicates the significant molecular motions of the former compounds. These results suggest the existence of the mobile residue trapped in the rigid epoxy networks at room temperatures. A similar phenomenon was observed in the case of residual monomer molecules remaining in the networks of its polymer, ${ }^{29}$ where the rigid polymer forms inhomogeneous glasses with high density clusters of tight, fully polymerized networks and pools of monomer.

The intensity ratio of the resonance at $55 \mathrm{ppm}$ (the unreacted epoxy carbons) to the resonances at $60-90 \mathrm{ppm}\left(\mathrm{C}_{\mathrm{B}}\right.$ and $\left.\mathrm{C}_{\mathrm{B}}{ }^{\prime}\right)$ in the $\mathrm{CP} / \mathrm{MAS}$ spectrum of Sample $\mathrm{G}$ was the same as that in its DD/MAS spectrum measured under the conditions sufficient to quantitative analysis (results not shown). Thus the conversion of the epoxy groups in ECC can be estimated from the integral intensities of these resonances in the $\mathrm{CP} / \mathrm{MAS}$ spectra. Defining $\mathrm{R}$ as the molar ratio of the ECC monomer of which both epoxy groups were reacted to the total ECC monomer added and assuming that no ECC reamins unreacted, the fraction of the epoxy groups of the ECC monomers unreacted, $r$, is expressed as;

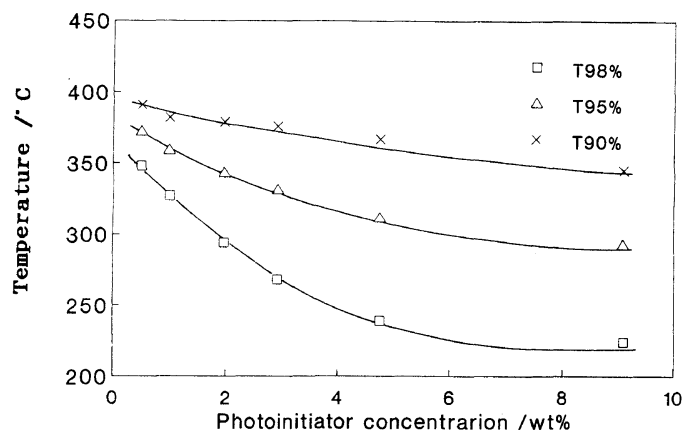

Figure 4. TPSHA concentration dependence of the thermal-decomposition temperatures, $T_{98 \%}, T_{95 \%}$, and $T_{90 \%}$, of the cured samples.

$$
r=\frac{Y}{X\{4 R / 5+2(1-R) / 3\}+Y}
$$

where $X$ and $Y$ are the intensities of the resonances at $60-90 \mathrm{ppm}$ and the resonance at $55 \mathrm{ppm}$, respectively. Considering that $R » 1-R$, eq 1 is simplified as;

$$
r=5 Y /(4 X+5 Y)
$$

The $r$ values calculated using eq 2 are listed in Table I. Although Samples A, B, and G were cured incompletely, their conversions are relatively high $(97.4-98.1 \%)$. The calculation of the $r$ values shows that the samples only in the range of the initiator concentration of $1-5 \mathrm{wt} \%$ were completely cured and the other samples were cured imcompletely.

\section{Thermal Gravimetric Analysis}

In Figure 4 are shown the thermal-decomposition temperature, $T_{98 \%}, T_{95 \%}$, and $T_{90 \%}$ of the cured samples as a function of the TPSHA concentration. The thermal stability of the samples becomes worse as the initiator concentration increases, though the chemical structure of the epoxy polymer is independent of the concentration. Furthermore, the trend of $T_{90 \%}$, in contrast with that of $T_{98 \%}$, is relatively independent of the initiator concentration. In fact, the difference of $T_{90 \%}$ between Samples A and $\mathrm{G}$ is $46^{\circ} \mathrm{C}$, while what of $T_{98 \%}$ is $124^{\circ} \mathrm{C}$. The thermal-decomposition 


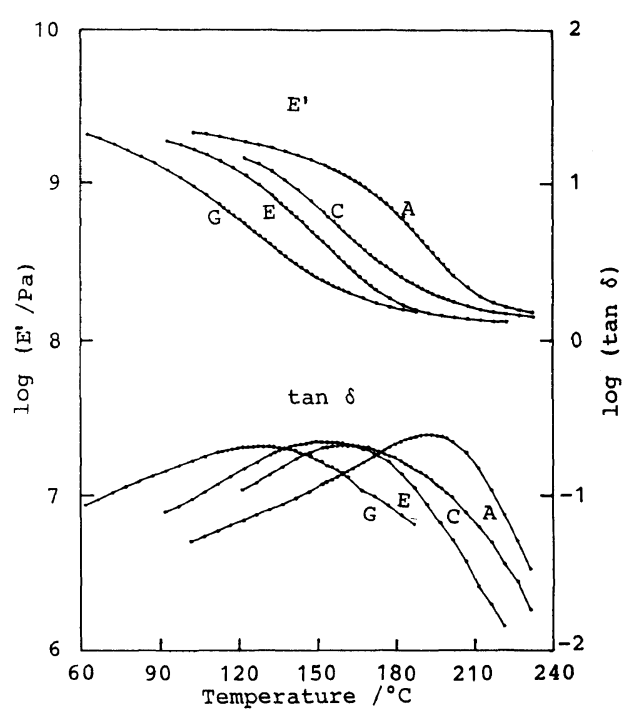

Figure 5. Temperature dependence of the storage Young's modulus $\left(E^{\prime}\right)$ and loss tangent $(\tan \delta$ ) for cured Sample A, Sample C, Sample E, and Sample G.

at the first stage is strongly affected by the initiator concentration, thus is dominated by the TPSHA residue rather than the epoxy polymer.

\section{Dynamic Mechanical Properties}

In Figure 5 are shown the storage Young's modulus, $E^{\prime}$, and the loss tangent, $\tan \delta$, in the temperature range covering the glass-transition region. Both curves shifts to lower temperature and the $\tan \delta$-termperature curve becomes broader, as the initiator concentration increases. The glass-transition temperatures, $T_{\mathrm{g}}$, obtained by the $\tan \delta$ curves are listed in Table I. The difference of $T_{\mathrm{g}}$ between Samples A and $\mathrm{G}$ is $66^{\circ} \mathrm{C}$. The TPSHA concentration exhibits a strong influence on $T_{\mathrm{g}}$.

The glass-transition temperature of polymer is, in general, affected by the factors as follows; observation time (or frequency), molecular weight, crystallinity, and species of plasticizer. $^{46}$ The dynamic mechanical measurements of all samples were carried out at $1 \mathrm{~Hz}$ constantly. Furthermore, the UV cured epoxy polymer is completely amorphous, thus the degree of crystallinity is nil in all samples. Hence the effects of the observation time and the crystallinity on the $T_{\mathrm{g}}$ can be ruled out in this case. The molecular weight was replaced by the molecular weight between crosslinks, $M_{\mathrm{C}}$, or crosslinking density, $\rho\left(=d / M_{\mathrm{C}}\right.$, where $d$ is the density of polymer) in the case of crosslinked polymers. The crosslinking density of the sample is given by the temperature at rubber state, $T_{\mathrm{r}}$, and the storage modulus at $T_{\mathrm{r}}, E_{\mathrm{r}}{ }^{46-48}$

$$
\rho=E_{\mathrm{r}} /\left(3 R T_{\mathrm{r}}\right)
$$

where $R$ is gas constant. $T_{\mathrm{r}}$ was set as $T_{\mathrm{g}}$ $+40^{\circ} \mathrm{C}$. The values of $E_{\mathrm{r}}$ and $\rho$ are listed in Table I. The $\rho$ values are almost constant irrespective of the initiator concentration. Therefore, the crosslinking density should be ignored as the factor which affects the $T_{\mathrm{g}}$ of the samples used here. The mean $M_{\mathrm{C}}$ value in the samples was calculated to be 83 with the density of the sample, $1.2 \mathrm{~g} \mathrm{~cm}^{-3}$. If the ester linkage in the ECC molecule is regarded as a crosslinking, there are 3 crosslinkings per ECC monomer unit in the cured sample. Since the molecular weight of ECC is 252 , the $M_{\mathrm{C}}$ value of the sample was calculated to be $84(=252 / 3)$, and is in good agreement with the experimental value.

The $T_{\mathrm{g}}$ shift of the samples was then interpreted as the plasticization effect of the TPSHA residue. Boyer and Spencer ${ }^{49}$ showed that the effect of plasticizer on the $T_{\mathrm{g}}$ can be expressed as

$$
T_{\mathrm{g}_{1}}^{-1}=T_{\mathrm{g}_{2}}^{-1}-k w^{1 / 2}
$$

where $T_{\mathrm{g}_{1}}$ and $T_{\mathrm{g}_{2}}$ are the $T_{\mathrm{g}}$ 's of polymer with and without plasticizer, respectively, $w$ is weight fraction of polymer, and $k$ is a constant. The plot of square root of the $w$ values against the reciprocal absolute temperatures of $T_{\mathrm{g}}$ is shown in Figure 6 . The data were found to be fitted by two straight line below $164^{\circ} \mathrm{C}$, while the curve seems to be saturated above the temperature. The fact that the data were fitted to the straight lines verifies the plasticization 


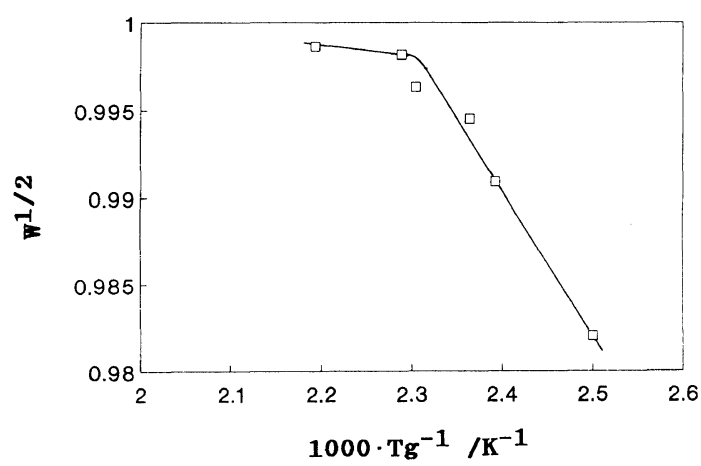

Figure 6. Glass-transition temperature dependence of square root of the weight fraction of polymer in the cured samples.

effect of the TPSHA residue on the UV cured epoxy polymers. The broadening of the tan $\delta$-temperature curve in Figure 5 are often observed when a plasticizer is added in polymer.

${ }^{13} C N M R$ Relaxation Times: $T_{1}^{\mathrm{C}}, T_{1 \rho}^{\mathrm{C}}$

The ${ }^{13} \mathrm{C}$ NMR spin-lattice relaxation times in the laboratory frame $(70 \mathrm{MHz}), T_{1}^{\mathrm{C}}$, and in the rotating frame $(60 \mathrm{kHz}), T_{1 \rho}^{\mathrm{C}}$, of the cured samples are plotted in Figures 7 and 8, respectively, against the TPSHA concentration. A mean relaxation time was calculated from the variation of integral intenstity of the whole $\mathrm{C}_{\mathrm{A}}$ pattern $(10-50 \mathrm{ppm})$ or the whole $\mathrm{C}_{\mathrm{B}}$ and $\mathrm{C}_{\mathrm{B}}{ }^{\prime}$ pattern $(60-90 \mathrm{ppm})$.

There is a marked effect of the $T_{1}^{\mathrm{C}}$ on the initator concentration below $2 \mathrm{wt} \%$, while the $T_{1}^{\mathrm{C}}$ is relatively independent of the concentration above $2 \mathrm{wt} \%$, as shown in Figure 7 . The trend of the $T_{1}^{\mathrm{C}}$ above $2 \mathrm{wt} \%$ indicates that the TPSHA residue negligibly affects on the localized motions of both the cyclohexyl ring and the crosslinking in the cured sample. This is the same phenomenon as the case of PMMA-plasticizer systems reported by Edzes and Veeman ${ }^{26}$ in which increased mobility of the polymer in the presence of a plasticizer is not reflected in significant changes in $T_{1}^{\mathrm{C}}$. On the other hand, the TPSHA residue restrains the megahertz motions of the entire epoxy

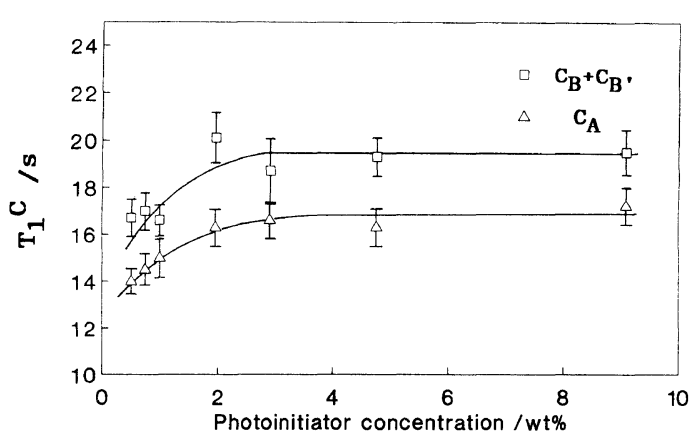

Figure 7. TPSHA concentration dependence of the ${ }^{13} \mathrm{C}$ spin-lattice relaxation time, $T_{1}^{\mathrm{C}}$, of the cured samples.

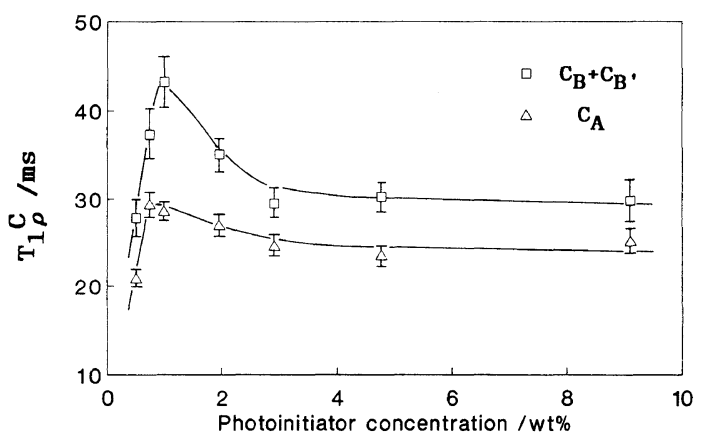

Figure 8. TPSHA concentration dependence of the ${ }^{13} \mathrm{C}$ spin-lattice relaxation time in the rotating frame, $T_{1 \rho}^{\mathrm{C}}$, of the cured samples.

polymer at room temperatures below the initiator concentration of $2 \mathrm{wt} \%$. The suppression of the molecular motions by the addition of a low molecular weight diluent is known as antiplasticization. ${ }^{50-52}$ Belfiore et al. ${ }^{27}$ reported that antiplasticization substantially affects the megahertz mobility of polycarbonate at $25^{\circ} \mathrm{C}$. Consequently, the $T_{1}^{\mathrm{C}}$ trend of the samples revealed that the TPSHA residue acts as antiplasticizer below $2 \mathrm{wt} \%$.

This phenomenon was more clearly observed by the spin-lattice relaxation experiments in the rotating frame, as shown in Figure 8. We confirmed by the variable spin-lock field experiments ${ }^{20}$ that the $T_{1 \rho}^{\mathrm{C}}$ of the cured samples is dominated by spin-lattice relaxation, therefore the relaxation parameter is sensitive to molecular motions in the kilohertz regime. The 
molecular motions of the cyclohexyl ring was reported to result from the process of internal ring inversion in a solid polyacrylates. ${ }^{38}$ The rise of the $T_{1 \rho}^{\mathrm{C}}$ of both the cyclohexyl ring and the crosslinking in the cured samples was observed as the initiator concentration increases in the range of $0.5-1 \mathrm{wt} \%$, while the $T_{1 \rho}^{\mathrm{C}}$ was decreased above the concentration of $1-2 \mathrm{wt} \%$. This trend clearly indicates the antiplasticization and plasticization effects of the TPSHA residue. Sefcik et al. ${ }^{28}$ reported by using ${ }^{13} \mathrm{C}$ NMR rotating frame relaxation experiments that the cooperative main-chian molecular motions of poly(vinyl chloride) are reduced when the additive behaves as an antiplasticizer and are increased when the polymer is plasticized. The work of Belfiore $e t$ $a l .{ }^{27}$ on polycarbonate-diluent systems and Allen et al. ${ }^{29}$ on poly[oligo(ethylene glycol)dimethacrylates] - its residual monomer systems showed similar trends of $T_{1 \rho}^{\mathrm{C}}$. In addition, the diluent which has a flat molecular structure with ring structures empirically acts as strong antiplasticizer. ${ }^{53}$ The molecules of TPSHA and its fragments meet this criterion.

\section{CONCLUSION}

At the TPSHA concentrations below $1 \mathrm{wt} \%$, the photopolymerization of ECC was relatively slow and the heat of the photopolymerization was highly affected by the concentration. However, there was no significant effect of the TPSHA concentration on the photoreactivity of the samples in the concentration range of $1-9 \mathrm{wt} \%$.

The CP/MAS ${ }^{13} \mathrm{C}$ NMR spectra showed that there is no significant difference in the chemical structure among the cured samples in the TPSHA concentration range of $0.5-9 \mathrm{wt} \%$. The conversion of the samples was calculated from the resonance intensity in the CP/MAS spectra. All samples were cured almost completely. The PST/MAS spectra revealed the existence of the mobile TPSHA residue trapped in the rigid epoxy networks. The thermal gravimetric analysis showed that the thermal stability of the cured samples becomes worse as the TPSHA concentration increases, indicating that the thermal-decomposition at the first stage is dominated by the TPSHA residue rather than the epoxy polymers.

The TPSHA concentration strongly influences on the glass-transition temperature, $T_{\mathrm{g}}$, of the cured samples. The $T_{\mathrm{g}}$ shift of the samples was interpreted as the plasticization effect of the TPSHA residue. The ${ }^{13} \mathrm{C}$ NMR spin-lattice relaxation time and spin-lattice relaxation time in the rotating frame provided information on the molecular motions of the epoxy polymers, indicating that the TPSHA residue acts as plasticizer above the TPSHA concentration of approximately $2 \mathrm{wt} \%$, while it acts as antiplasticizer below this concentration.

The physical properties, for instance brittleness, of UV cured epoxy resins may be affected by the photoinitiator concentration, thus we must pay attention to the physical properties as well as the cure rate when compounding a UV curable system.

Acknowledgments. The authors thank Mr. Fumio Sakurai at Electric Division Laboratory, Sumitomo 3M Ltd., for helpful discussions. They also thank Mr. Yoshio Okumura at Corporate Research Laboratory, Sumitomo $3 \mathrm{M}$ Ltd., for the TG measurements. They acknowledge Sumitomo 3M Ltd., for the use of the photo-DSC system, dynamic mechanical analyzer, and UV irradiation instruments. One (A.U.) of them thanks Sumitomo 3M Ltd., for granting him a leave from the company to develop this study at Tokyo Institute of Technology.

\section{REFERENCES}

1. J. V. Crivello, in "UV Curing, Science and Technology," P. S. Pappas, Ed., Marketing Corp., CT, 1978, Chapter 2.

2. W. R. Watt, in "UV Curing, Science and Technology Vol. 2," P. S. Pappas, Ed., Marketing Corp., CT, 1985, Chapter 6. 
3. J. V. Crivello, J. H. W. Lam, J. E. Moore, and S. H. Schroeter, J. Radiat. Curing, 5, 2 (1978).

4. J. V. Crivello and J. H. W. Lam, J. Polym. Sci., Polym. Lett. Ed., 17, 759 (1979).

5. J. V. Crivello and J. H. W. Lam, J. Polym. Sci., Polym. Chem. Ed., 17, 977 (1979).

6. J. V. Crivello and J. L. Lee, Polym. J., 17, 73 (1985).

7. S. P. Pappas, L. R. Gatechair, and J. H. Jilek, J. Polym. Sci., Polym. Chem. Ed., 22, 77 (1984).

8. J. V. Crivello, J. H. W. Lam, and C. N. Volante, J. Radiat. Curing, 4, 2 (1977).

9. J. E. Moore, in "UV Curing, Science and Technology," P. S. Pappas, Ed., Marketing Corp., CT, 1978, Chapter 5.

10. A. J. Evans, C. Armstrong, and R. J. Tolman, J. Oil Colloid Chem. Assoc., 61, 251 (1978).

11. F. R. Wight and G. W. Hicks, Polym. Eng. Sci., 18, 378 (1978).

12. G. R. Tryson and A. R. Shultz, J. Polym. Sci., Polym. Phys. Ed., 17, 2059 (1979).

13. D. D. Le, J. Radiat. Curing, 12, 2 (1985).

14. B. K. Appelt and M. J. M. Abadie, Polym. Composite, 25, 931 (1985).

15. W. R. Watt, in "Epoxy Resin Chemistry," R. S. Bauer, Ed., The American Chemical Society, Wachington, D. C., 1979, Chapter 2.

16. S. R. Hartmann and E. L. Hahn, Phys. Rev., 128, 2042 (1962).

17. A. Pines, M. G. Gibby, and J. S. Waugh, J. Chem. Phys., 59, 569 (1973).

18. E. R. Andrew, Prog. Nucl. Magn. Reson. Spectrosc., 8, 1 (1971).

19. J. Schefer, E. O. Stejskal, and R. Buchdahl, Macromolecules, 8, 291 (1975).

20. A. N. Garroway, W. B. Moniz, and H. A. Resing, Faraday Symp. Chem. Soc., 13, 63 (1978).

21. A. N. Garroway, W. B. Moniz, and H. A. Resing, in "Carbon-13 NMR in Polymer Science," W. M. Pasika, Ed., The Amrican Chemical Society, Washington, D. C., 1979, p 67.

22. A. N. Garroway, W. M. Ritchey, and W. B. Moniz, Macromolecules, 15, 1051 (1982).

23. L. A. Weisenberger and J. L. Koening, J. Polym. Sci, B, Polym. Phys., 26, 771 (1988).

24. E. A. Mertzel, D. R. Perchak, W. M. Ritchey, and J. L. Koening, Ind. Eng. Chem. Res., 27, 586(1988).

25. T. R. Steger, J. Schaefer, E. O. Stejskal, and R. A. McKay, Macromolecules, 13, 1127 (1980).

26. H. T. Edzes and W. S. Veeman, Polym. Bull., 5, 255 (1981).

27. L. A. Belfiore, P. M. Henrichs, D. J. Massa, N. Zumbulyadis, W. P. Rothwell, and S. L. Cooper, Macromolecules, 16, 1744 (1983).

28. M. D. Sefcik, J. Schaefer, F. L. May, D. Raucher, and S. M. Dub, J. Polym. Sci., Polym. Phys. Ed., 21, 1041 (1983).
29. P. E. M. Allen, G. P. Simon, D. R. G. Williams, and E. H. Williams, Macromolecules, 22, 809 (1989).

30. J. Schaefer, E. O. Stejskal, and R. Buchdahl, Macromolecules, 10, 384 (1977).

31. E. O. Stejskal, J. Schaefer, and T. R. Steger, Faraday Symp. Chem. Soc., 13, 56 (1978).

32. M. D. Sefcik, J. Schaefer, E. O. Stejskal, and R. A. McKay, Macromolecules, 13, 1132 (1980).

33. M. D. Sefcik and J. Schaefer, J. Polym. Sci., Polym. Phys. Ed., 21, 1055 (1983).

34. J. Schaefer, M. D. Sefcik, E. O. Stejskal, R. A. McKay, W. T. Dixon, and R. E. Cais, Macromolecules, 17, 1107 (1984).

35. J. Schaefer, M. D. Sefcik, E. O. Stejskal, and R. A. McKay, Macromolecules, 17, 1118 (1984).

36. J. Schaefer, M. D. Sefcik, E. O. Stejskal, R. A. McKay, W. T. Dixon, and R. E. Cais, in "NMR and Macromolecules", J. C. Randall, Ed., The Amrican Chemical Society, Washington, D. C., 1984, p 43.

37. D. L. Vanderhart and A. N. Garroway, J. Chem. Phys., 71, 2773 (1979).

38. F. Laupretre, L. Monnerie, and J. Virlet, Macromolecules, 17, 1397 (1984).

39. W. W. Fleming, J. R. Lyerla, and C. S. Yannoni, in "NMR and Macromolecules," J. C. Randall, Ed. The Amrican Chemical Society, Washington, D. C., 1984, p 83.

40. P. E. M. Allen, G. P. Simon, D. R. G. Williams, and E. H. Williams, Polym. Bull., 11, 593 (1984).

41. P. E. M. Allen, G. P. Simon, D. R. G. Williams, and E. H. Williams, Eur. Polym. J., 22, 549 (1986).

42. R. Kitamaru, F. Horii, and K. Murayama, Macromolecules, 19, 636 (1986).

43. T. Fujito, K. Deguchi, M. Ohuchi, M. Imanari, and M. J. Albright, The 20th Meeting of NMR, Tokyo, $1981, \mathrm{p} 68$.

44. D. A. Torchia, J. Mag. Reson., 30, 613 (1978).

45. A. Udagawa, Y. Yamamoto, and R. Chûjô, Polymer, 31, 2425 (1990).

46. L. E. Nielsen, "Mechanical Properties of Polymers and Composites," Marcel Dekker, Inc., New York, N. Y., 1975.

47. T. Murayama and J. P. Bell, J. Polym. Sci., A-2, 8, 437 (1970).

48. N. Kinjo, M. Ogata, S. Numata, and T. Yokoyame, Netsukôkasei Jushi, 6, 157 (1985).

49. R. F. Boyer and R. S. Spencer, J. Polym. Sci., 2, 157 (1947).

50. N. Kinjo and T. Nakagawa, Polym. J., 4, 143 (1973).

51. N. Hata, R. Yamauchi, and J. Kumanotani, J. Appl. Polym. Sci., 17, 2173 (1973).

52. N. Hata and J. Kumanotani, J. Appl. Polym. Sci., 211257 (1977).

53. W. J. Jackson Jr. and J. R. Caldwell, J. Appl. Polym. Sci., 11, 211 (1967). 